\title{
Gene targeting in livestock
}

\author{
A. J. Thomson, M. M. Marques and J. McWhir ${ }^{1 *}$ \\ Department of Gene Expression and Development, Roslin Institute, Roslin, \\ Midlothian EH25 9PS, UK
}

\begin{abstract}
The development of nuclear transfer from tissue culture cells in livestock made it possible in principle to produce animals with subtle, directed genetic changes by in vitro modification of nuclear donor cells. In the short period since nuclear transfer was first performed, gene targeting in livestock has become a reality. Although gene targeting has immediate potential in biotechnology, it is unclear whether there are practical agricultural applications, at present. The first livestock targeting experiments have been directed at engineering animals either to render their organs immunologically compatible for human transplantation, or for improving the commercial production of recombinant proteins in the transgenic mammary gland. All successful examples of targeting have involved target loci that are expressed in the nuclear donor cell line. Two important barriers to the further development of this technology are adapting protocols for non-expressed genes and modifying procedures to enhance the lifespan of targeted cells in vitro. This review provides data that illustrate the difficulty in targeting non-expressed genes and discusses some of the practical issues associated with providing targeted nuclear donor cells that are competent for nuclear transfer.
\end{abstract}

\section{Introduction}

In 1982, Palmiter and colleagues reported the birth of transgenic mice that expressed human growth hormone and that grew to a mature size of up to twice that of their non-transgenic littermates. This report was met with mixed reaction. Within the agricultural research community some researchers saw potential for improving the efficiency of animal production. However, when similar experiments were repeated in livestock, the resulting transgenic pigs showed minimal improvement in feed efficiency and suffered a variety of side effects with serious consequences for animal welfare (Hammer et al., 1985). A summary of the significant milestones in the development of transgenic technology is shown (Fig. 1). Arguably, there are still no good examples of transgenic approaches leading to agricultural improvement and it has really been the pharmaceutical/biotechnology potential of transgenic farm animals that has fuelled the further development of this technology. The production of pharmaceutical proteins in the mammary glands of transgenic sheep and cattle has developed into a new 


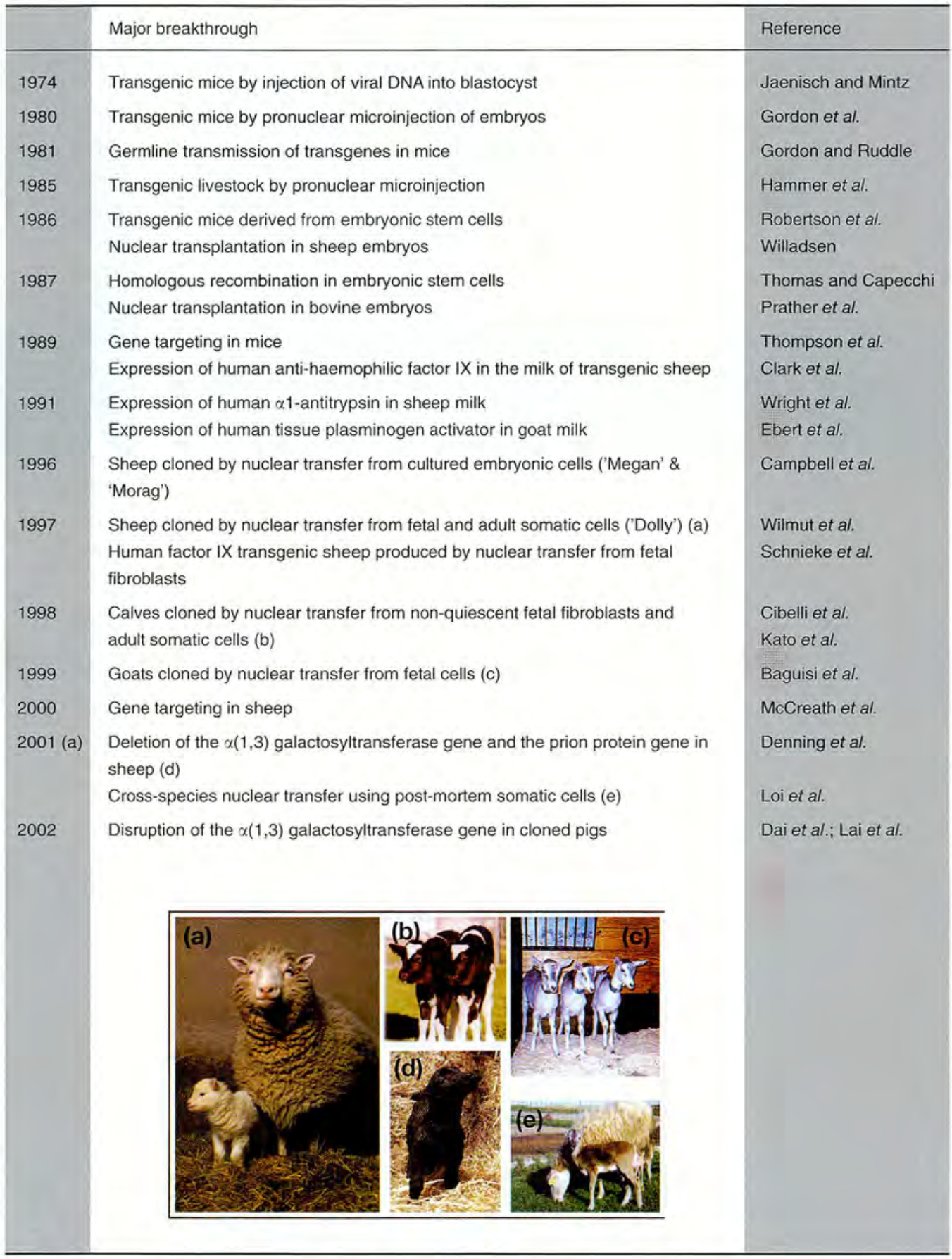

Fig. 1. Significant milestones in the development of cloning technology.

industry and has underpinned the development of cloning of large animals by nuclear transfer from somatic cells. Although the announcement of the birth of Dolly in 1997 after nuclear transfer from an adult cell (Wilmut et al., 1997) was widely seen as a prelude to possible human cloning, Dolly was actually inspired by a very practical interest - development of 
cell-based transgenesis to facilitate gene targeting in livestock. The search for embryonic stem cells in livestock has also been motivated by this same interest in gene targeting. Why gene targeting? Why stem cells? Should we revisit the potential of these technologies in animal production?

A full review of the potential applications of gene targeting in livestock is beyond the scope of this paper. Indeed, a more appropriate source of such a review would be those scientists more directly involved in agricultural research of which there are several examples (Piedrahita, 2000; Di Berardino, 2001). The main objective of the present review is to describe the 'state of the art' of gene targeting in livestock and hopefully to stimulate some discussion of the potential for this technology in animal production and reproduction.

\section{Cell-based transgenesis}

The introduction of transgenes to mammalian embryos by pronuclear injection is an imprecise technique, which has changed little since its inception. Pronuclear injection is also inefficient as only $1-10 \%$ of injected transferred livestock embryos give rise to transgenic offspring. Perhaps the greatest deficiency of this technique is that there is no experimental control over the site of incorporation of the transgene or of transgene copy number. Hence the level and pattern of expression is highly variable. In practice, up to ten transgenic founders may be required to ensure that one animal has appropriate expression. The main difficulty with this technique is the unpredictable transgene expression, which arises as a direct consequence of random integration. It would be preferable to direct single copy transgenes to a specific site in the genome where the pattern and level of transgene expression can be predicted or to make use of existing transcriptional machinery by targeting an open reading frame into an appropriate endogenous promoter. This is the experimental process of 'gene targeting' in which the inclusion in a transgenic construct of regions of homology to endogenous sequence mediates rare insertion events by homologous recombination.

The introduction of transgenes to tissue culture cells (cell-based transgenesis) rather than to embryos allows the use of mass methods of transfection, such as electroporation, in which thousands of transgenic clones are generated instantaneously. This procedure provides the opportunity to generate precise genetic change simply because it is adaptable to the development of high throughput rapid screening for events such as homologous recombination that occur at low frequency. The obvious disadvantage of cell-based transgenesis per se is that transgenic animals need to be generated from the genetically modified cell lines. In principle, there are now two ways in which this can be achieved: embryonic stem cells and nuclear transfer.

\section{Embryonic stem cells}

In 1981, Evans and Kaufman showed that permanent undifferentiated cell lines could be derived from early mouse embryos. These so called embryonic stem (ES) cells were characterized by a remarkable set of properties: (i) they could be cultured indefinitely without differentiation and without the accumulation of karyotypic abnormalities, and (ii) when reintroduced to the preimplantation embryo, they would resume their normal differentiation programme and participate in normal development, including contribution to functional germ cells. Germ line competence is referred to as totipotentiality. Hence, totipotential ES cells offered an alternative, cell-based, route to whole animal (germline) transgenesis. The murine ES system has now become a routine laboratory tool for the generation of 'knockout' mice in which gene function can be investigated by studying the developmental consequences of disrupting the target 
A. J. Thomson et al.

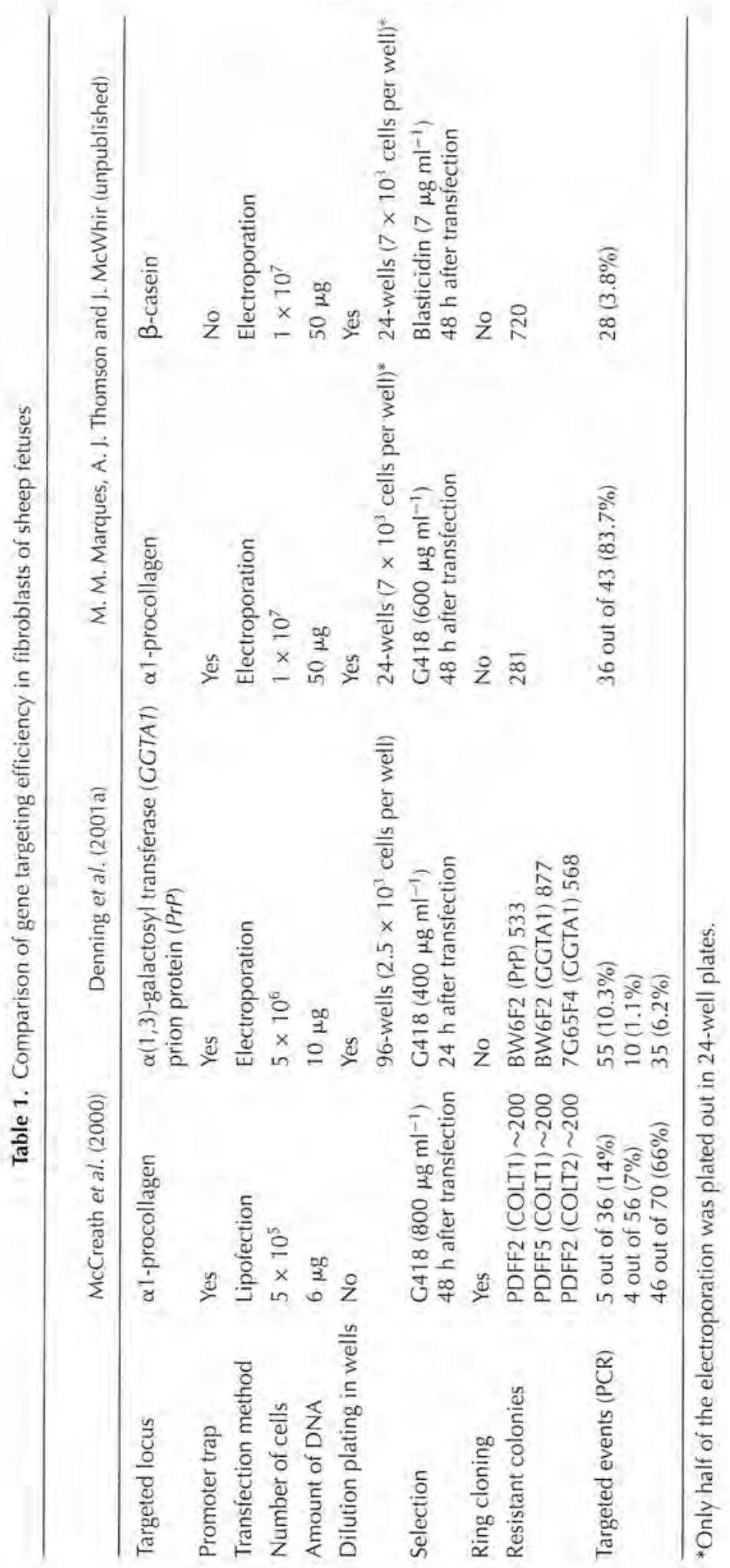


gene. Attempts to develop a similar system in livestock species have invariably floundered at the germ line transmission step. Although there are numerous reports of the development of ES-like lines with apparent multipotentiality in vitro, no putative ES lines have given rise to functional ES-derived germ cells (germline transmission) in chimaeric animals from any species other than the mouse. Until the development of nuclear transfer this represented an absolute barrier to gene targeting in species other than mouse.

\section{Nuclear transfer and gene targeting}

Transgenic sheep (Schnieke et al,, 1997), calves (Cibelli et al., 1998; Brink et al., 2000) and goats (Keefer et al., 2001) have all been generated by nuclear transfer from transgenic fetal fibroblasts, modified by the addition of transgenes. This technique involves the fusion of a genetically modified nuclear donor cell with an enucleated oocyte to generate a 'reconstructed embryo', which is then transferred to a recipient female after a period of in vitro culture. More recently several groups have shown the successful generation of gene targeted nuclear donor cells (Tables 1 and 2) with insertions directed to the ovine $\alpha 1$ (I) procollagen (Col1A1) locus (McCreath et al., 2000), the ovine $\alpha 1,3$ galactosyltransferase (GGTA1) and prion protein $(P r P)$ genes (Denning et al., 2001a), and the porcine GGTA1 gene (Dai et al., 2002; Harrison et al., 2002). Crucially, only Col1A1 targeted ovine cells gave rise to viable animals that subsequently survived to adulthood. Slightly more encouraging are the porcine data (Dai et al., 2002) in which five of seven liveborn piglets survived to adulthood; however, it is perhaps premature to conclude that this represents a true species difference.

A particular difficulty in the development of targeting procedures for fetal fibroblasts is premature senescence, which frequently makes it impossible to confirm the targeted event by Southern blot analysis before nuclear transfer. GGTA and PrP targeting in sheep, for example, and GGTA in pigs (Denning et al., 2001a,b; Harrison et al., 2002) could not be confirmed by Southern blot analysis. In the former example, targeting was confirmed only post hoc by analysis of fetal tissue, but crucially this depended upon prior nuclear transfer in the absence of that confirmation.

\section{Practical aspects of gene targeting in livestock}

\section{Association of developmental abnormality with the modification of nuclear donor cells}

Nuclear transfer is associated with developmental abnormalities, such as increased birth weight, longer gestation period, high perinatal mortality, congenital malformations and increased abortion rate (Van Reenen et al., 2001). Collectively, these effects are referred to as large offspring syndrome (LOS). This phenomenon is usually attributed to incomplete reprogramming, but may also arise as a result of accumulation of subkaryotypic abnormalities in cultured nuclear donor cells, to the loss of imprinting normally laid down during gametogenesis, or to both. Although there are few data, the incidence of LOS may increase with nuclear donor cells that are genetically modified. Of 14 liveborn lambs reported by McCreath et al. (2000) from targeted cells, only three survived beyond 6 months. Denning et al. (2001) reported that of seven targeted lambs born, the only survivor was killed for animal welfare reasons at 1 week of age. The same cell line used in these targeting experiments had previously given rise to clones that survived to adulthood. If single-cell cloning does impose an additional developmental burden, this can be explained in at least two ways. If only a proportion of nuclear donor cells are capable of being reprogrammed then that proportion may be closely 


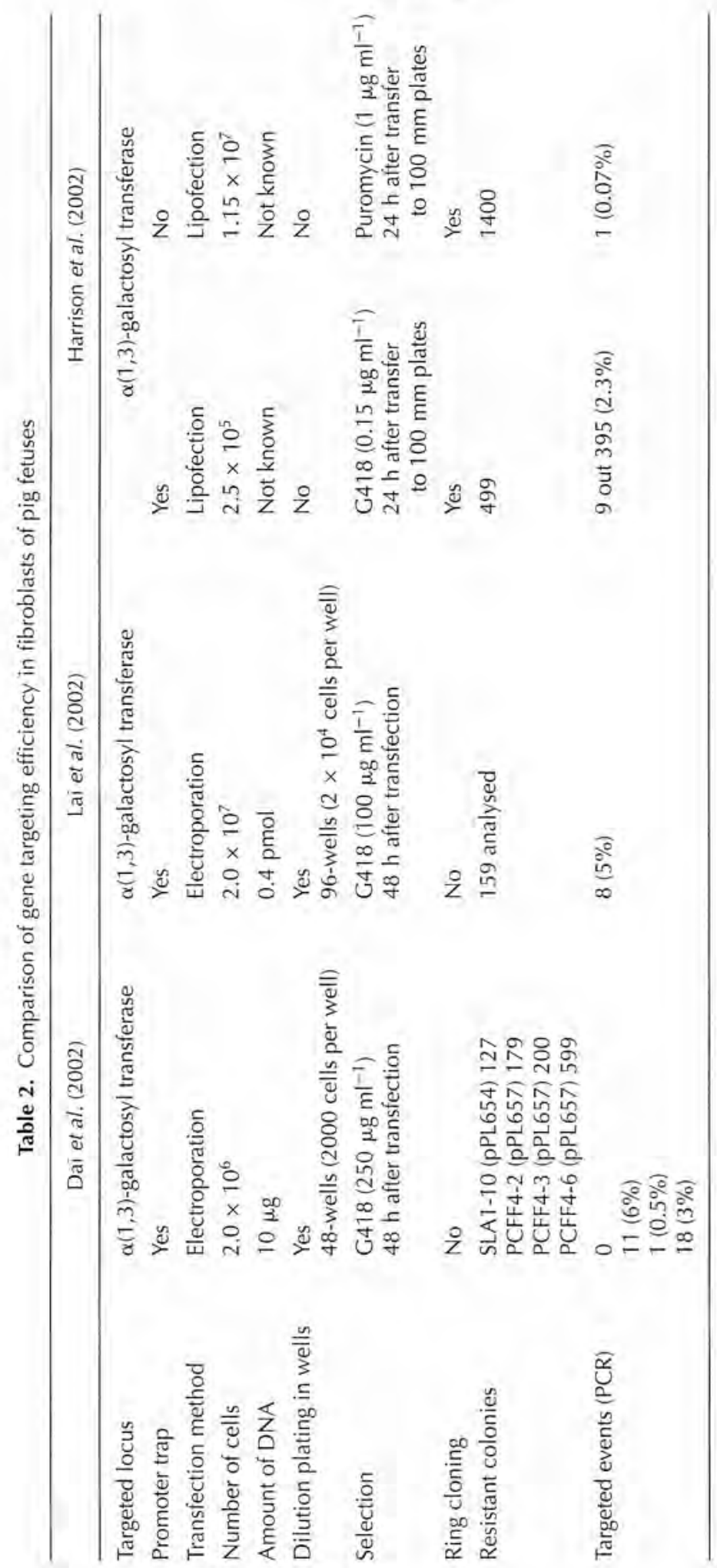



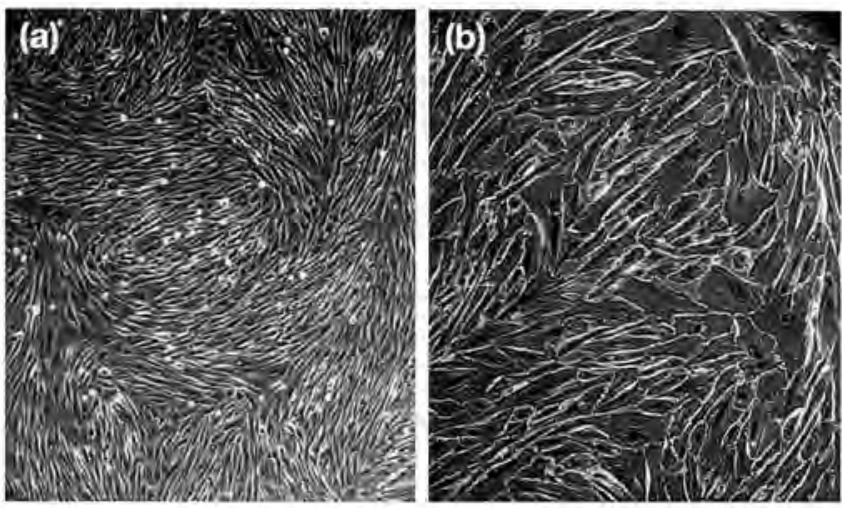

Fig. 2. Morphology of ovine fetal fibroblasts (PDFF2) after single cell cloning by selection for blasticidin resistance: (a) a non-senescent colony and (b) a senescing colony.

correlated with development to term and beyond. If that proportion is low, then there is a correspondingly high likelihood that any one subclone will be developmentally compromised. Alternatively, or in addition, the stress of subcloning may introduce new modifications, such as loss of imprint, that lead to developmental failure. In either event it is important to develop targeting protocols that reduce the period from transfection to identification of targeted cells and reduce the stress imposed by single-cell cloning during this period. The ideal targeting protocol would eliminate the subcloning step completely.

\section{Senescence and somatic cells}

Fetal fibroblasts from livestock species cease division (senesce) within 90-100 population doublings. Although this finding would appear to give a very large window for targeting experiments, it probably masks a situation in which senescence is ongoing even at early passage but is largely unnoticed as proliferating cells overtake the senescing population. However, such a dynamic becomes rapidly apparent after single-cell cloning in which typically almost $50 \%$ of the chosen colonies senesce within 1 week of isolation. A high but variable proportion of the remaining colonies subsequently senesce, and do not provide sufficient DNA for Southern blot analysis. Representative senescent and non-senescent single-cell colonies are shown (Fig. 2). Although the evidence is still anecdotal, we believe this problem arises as the cumulative effect of clonal variability in proliferative potential and the additional stress due to growth of cells at low density.

There is also concern that senescence may be more than simply a logistical problem, but may also be associated causally with developmental failure. Time in culture is known to be associated with the accumulation of both imprinting errors (Rideout et al,, 2001) and genetic abnormalities (Eggan et al., 2002). Cloning efficiency has been negatively correlated with passage number (Wilmut et al., 1997; McCreath et al., 2000; Denning et al., 2001a) although there are also reports to the converse (Kubota et al., 2000, Lanza et al., 2000). Research into the use of alternative cell populations, telomerization of fetal fibroblasts to extend doubling time or alternative methods of identifying targeted cells are all high priorities. 


\section{Strategies to overcome senescence}

Novel strategies are under investigation for the analysis of pooled cells in which singlecell cloning may be unnecessary or in which the underlying frequency of homologous recombination may be increased. This work is in its infancy and is not discussed here in detail. Other studies are investigating the potential for telomerization to improve the viability of clonally derived fetal fibroblast cells. One simple modification that markedly improves the proportion of colonies that continue to proliferate is to use a dilution plating targeting protocol (outlined in Fig. 3) to establish an average of 1-3 clones per well of a series of 24 well plates. This procedure has the disadvantage that most of the resulting clones are mixed and candidate targeted clones may also contain non-targeted cells. However, this technique has the advantage that clones remain vigorous and can provide sufficient DNA for Southern blot analysis.

An alternative solution may be the isolation of livestock-derived cells that do not senesceES cells. In mice, ES cells are ideally suited to genetic manipulation. Unlike fetal fibroblasts, ES cells proliferate indefinitely, and retain a normal euploid karyotype. Recently it has been shown that in mice ES cells may also be the preferred nuclear donor (Wakayama et al., 1999; Rideout et al., 2000; Eggan et al., 2001; Humpherys et al., 2001). This preference is probably because ES cells retain a chromatin structure similar to that of cells in the early embryo and require less reprogramming. These features of murine ES cells have renewed interest in isolating ES cells from farm animal species as a potential solution to senescence of nuclear donor cells. It would also overcome the difficulty in obtaining confirmation of targeted status by Southern blot analysis and possibly the developmental abnormalities associated with incorrect reprogramming.

\section{Targeting expressed genes in livestock}

We sought first to establish whether an expressed ovine gene (Co/TA7) could be targeted with both promoter trap and non-promoter trap strategies. PPL Therapeutics had previously targeted Col1A1 at high frequency in ovine fetal fibroblasts (McCreath et al., 2000). The Col1A1 targeting construct was modified so that it contained an additional selectable marker (blasticidin) driven by the SV 40 promoter (Fig. 4a). In this way the same cells could be compared, transfected with the same DNA, for promoter trap (G418 selection) and non-promoter trap (blasticidin selection). A representative Giemsa stained plate in which approximately $50 \%$ of wells give rise to colonies that comprise predominantly single-cell clones is shown (Fig. 4b). Targeted colonies were obtained under both forms of selection and therefore there is no reason to believe that a promoter trap per se is essential to successful targeting in ovine fetal fibroblast cells. However, because the non-promoter trap will always be associated with a high background of non-targeted clones, it is also inherently prone to an increase in false positives obtained by PCR analysis.

PCR analysis was performed using one primer within the neo cassette and a second primer within the upstream Col1A1 sequence (but outside the sequence included in the targeting construct) to identify targeted clones. Southern blot analysis of 15 clones that amplified the targeting-specific band (Fig. 4c) uses an internal probe within the $5^{\prime}$ homology and gives a targeting-specific band of $5 \mathrm{~kb}$ and a band of random size in non-targeted clones. Hence, clone 53 is confirmed as a random integrant by Southern blot analysis (Fig. 4c), but was originally diagnosed as a targeted clone by PCR analysis, This is most likely attributable to the presence of a minority of targeted cells within mixed clones, although it may also be due to PCR artefacts. These data demonstrate the danger of relying upon a PCR screen alone. 


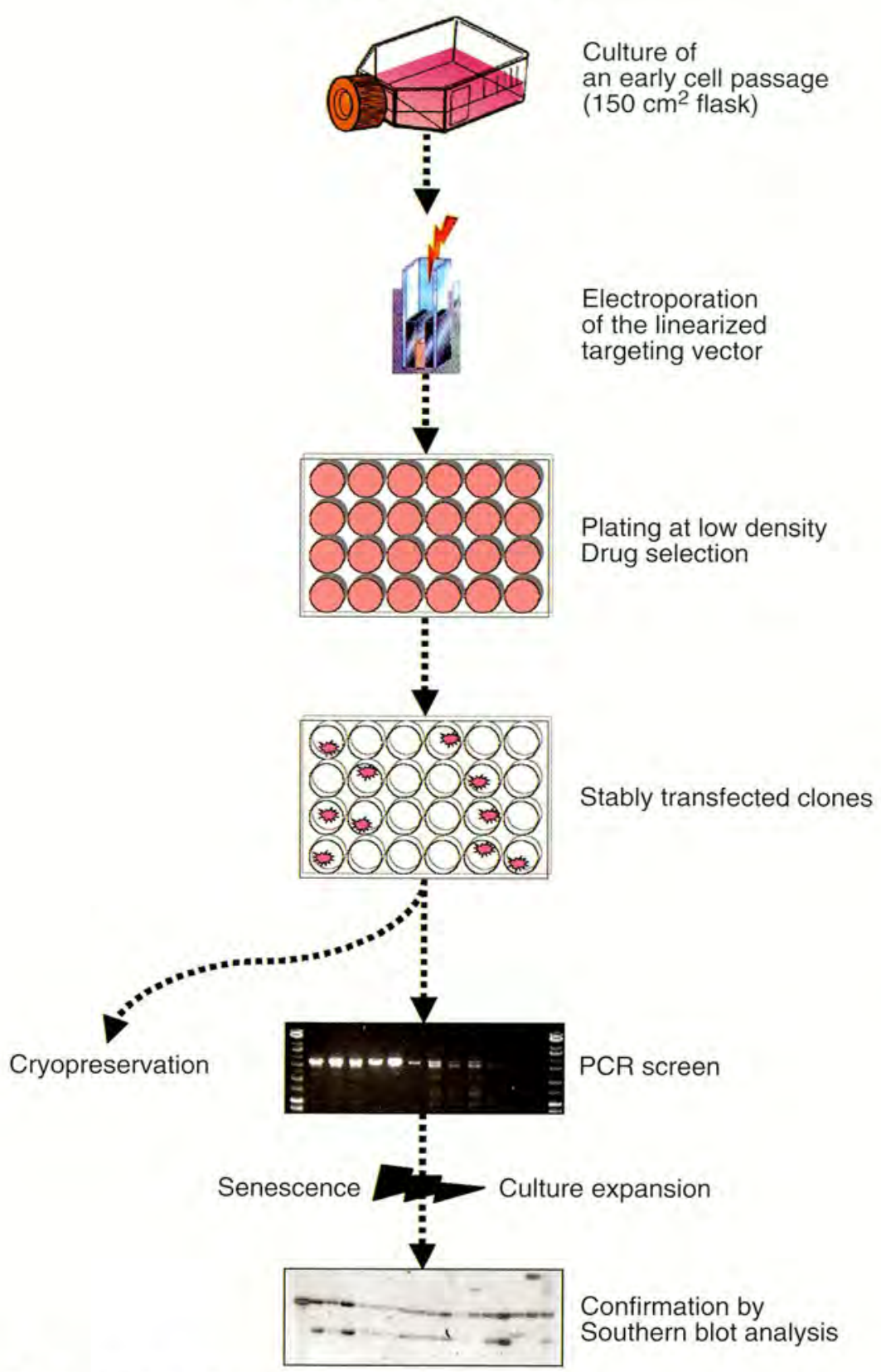

Fig. 3. Dilution plating targeting procedure.

When a similar analysis was performed from non-promoter trap clones, the proportion of false positives was higher, reflecting the inherent ability of the promoter trap to enrich for targeted clones and illustrating that the screening of non-promoter trap clones is complicated by a high incidence of artefacts. 


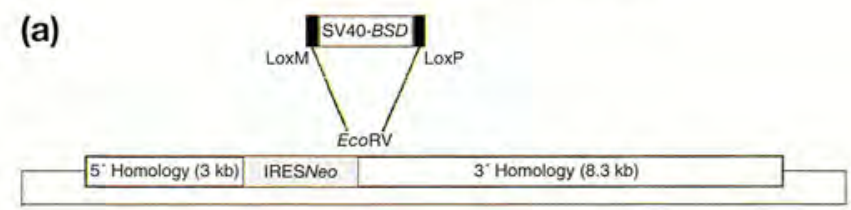

\section{COLT-1/BSD Targeting vector}

(b)

(c)

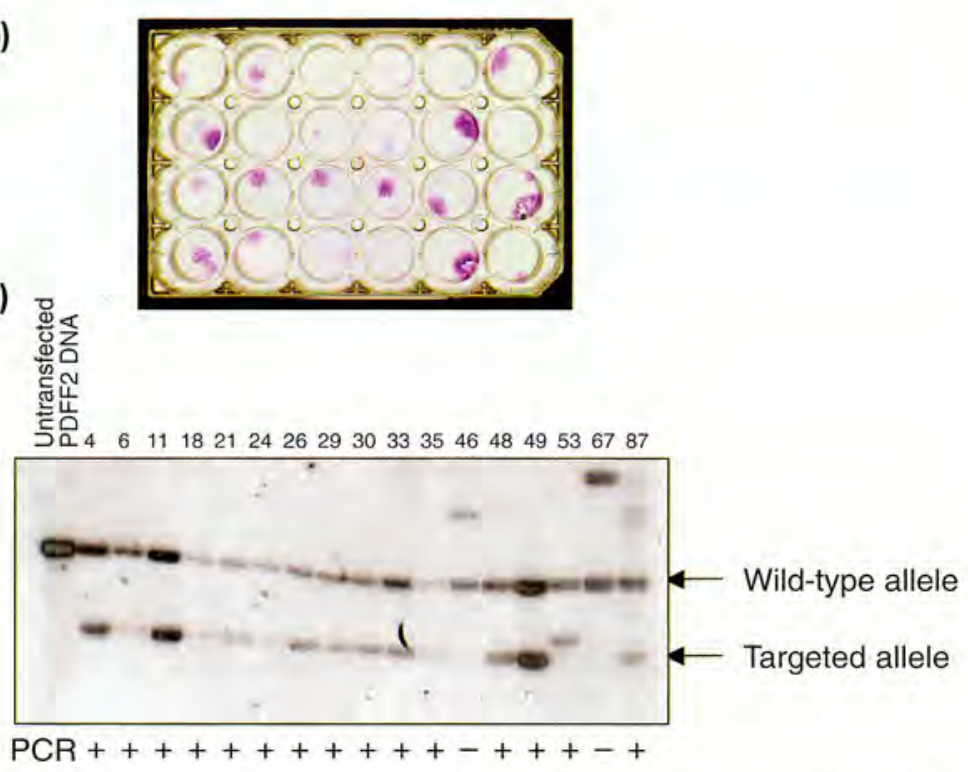

Fig. 4. Targeting an expressed gene ovine $\alpha 1$ (I) procollagen $(\mathrm{Co} / 1 \mathrm{~A} 1)$ with both promoter trap and non-promoter trap vectors. (a) Targeting construct in which the neo gene is driven by the promoter at the target locus (promoter trap) and the blasticidin selectable marker carries its own promoter (non-promoter trap). (b) Fixed and Giemsa-stained fetal fibroblast cells after dilution plating. The majority of wells appear to contain a single colony. (c) Southern blot analysis of clones from the promoter trap experiment that tested positive by PCR. Most, but not all (for example lane 46), are confirmed as targeted.

\section{Targeting unexpressed genes in livestock has not yet been accomplished}

To address the related problems of targeting unexpressed genes and of overcoming senescence, we previously attempted to target two unexpressed genes in sheep fetal fibroblasts and obtained no candidate targeted clones at either the cystic fibrosis transmembrane conductance regulator (CFTR) locus (S. Pells, unpublished) or the $\beta$-casein locus (A. J. Thomson and M. M. Marques, unpublished). There are presently no reports in the literature of targeted fetal fibroblasts in farm animal species at non-expressed genes.

In principle, the difficulty in targeting unexpressed genes can be accounted for in two ways. Targeting an expressed gene enables the use of a promoter trap vector in which expression of a selectable marker is dependent upon homologous recombination to provide transcriptional activation. This is only an option with an expressed target gene because the selectable marker 
uses the promoter of the target gene. The promoter trap provides very high enrichment for the targeted event because very few random integrants are capable of expressing the selectable marker. Even if the underlying frequency of targeting is low, such a strategy may mean that most of the surviving clones are actually targeted. For example at the Col1 At locus $>60 \%$ of the clones analysed were targeted (McCreath et al., 2000). Alternatively (or additionally) there may be features of the chromatin structure at certain unexpressed genes that render the target unavailable for homologous recombination. In the latter event, targeting frequency may be very low or even non-existent.

\section{Targeting $\beta$-casein in livestock}

We are interested in conducting gene targeting in ovine fetal fibroblasts to place transgenes at the $\beta$-casein locus, to provide high level, mammary-specific transgene expression. As $\beta$-casein expression is highly tissue- and stage-specific, the gene is not transcribed in fetal fibroblasts. Hence, the targeting construct (Fig. 5a) is necessarily a non-promoter trap in which selection is for the expression of a constitutively expressed blasticidin cassette that is expected to be active in both targeted and non-targeted cells. A large scale targeting experiment at the ovine $\beta$-casein locus was carried out using the dilution plating procedure. A PCR pre-screen identified 28 candidate-targeted clones out of 720 clones analysed. A representative panel of PCR-positive clones is shown (Fig. 5b). It was then confirmed by digestion with enzymes that cleave at known sites within the fragment that the targeting-specific band amplified from these samples was the expected $\beta$-casein fragment (Fig. $5 \mathrm{c}$ ). This finding would seem to provide convincing evidence of successful targeting at an unexpressed locus. However, the possibility could not be excluded of so-called 'jump' PCR in which a fragment polymerized non-geometrically from the blasticidin primer in a random site hybridizes with a fragment polymerized from the upstream primer but generated at the unmodified $\beta$-casein locus. Were such a hybrid to form then it would generate a product capable of geometric amplification and identical to the targeting-specific band. Although jump PCR is a formal explanation, it is unlikely that this actually occurs because multiple PCR reactions on the same clones invariably give rise to the same diagnostic fragment. In addition, this fragment cannot be generated artefactually by mixing the targeting construct with wild-type genomic DNA (A. J. Thomson and M. M. Marques, unpublished). Another possibility is that false positives result from mispriming due to fortuitous similarity between the sequence near the integration site and the upstream $\beta$-casein PCR primer.

Preliminary data after Southern blot analysis indicate that the candidate targeted clones (Fig. 5b) are not actually targeted (A. J. Thomson and M. M. Marques, unpublished). The provisional explanation of this result is that these clones contain a mixture of targeted and non-targeted cells and that the targeted cells are preferentially lost with culture. Although it is not clear why targeted clones should be at a growth disadvantage, the most likely explanation is that the chromatin structure at the inactive $\beta$-casein gene locus prevents longterm expression of the blasticidin resistance gene resulting in the senescence or death of the targeted cells. This finding highlights the importance of experimental detail. For example, if we had lower levels of blasticidin selection perhaps the targeted cells would have survived. Once again, this is a salutary lesson in the danger of over-reliance on PCR data alone-particularly with a non-promoter trap strategy. It appears that the dilution plating technique, although very successful in addressing the problem of senescence, may have led to predominantly mixed clones and eventual loss of targeted cells. This problem is being addressed by further optimization of the dilution plating procedure. 
(a)

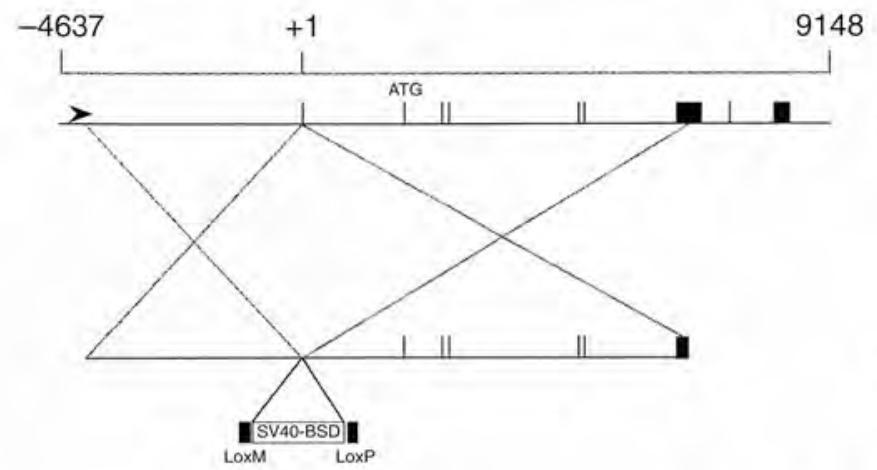

$\beta$-Casein locus

Targeting vector

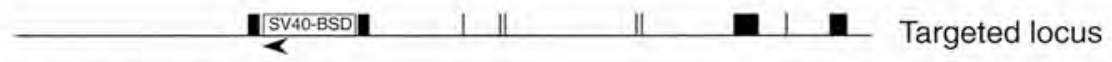

PCR primers

(b)

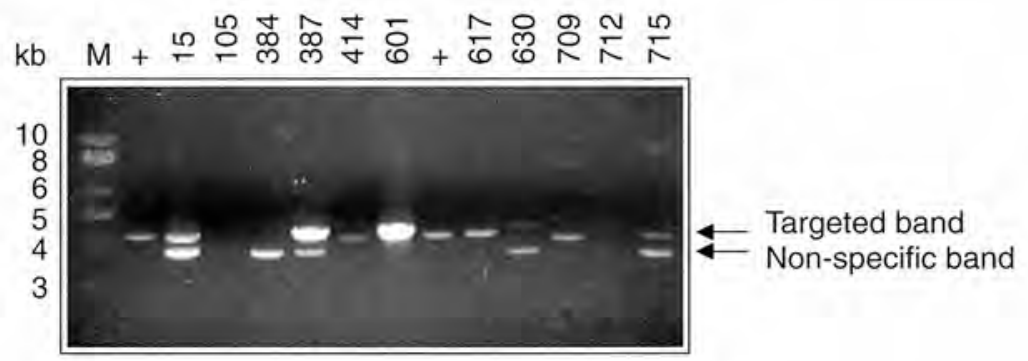

(c)

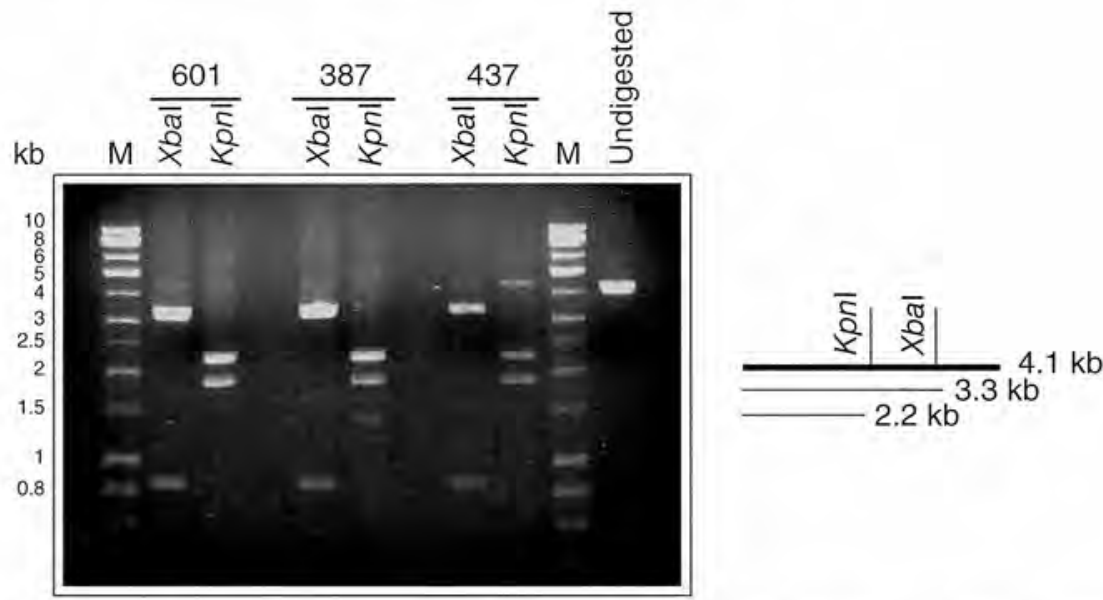

Fig. 5. $\beta$-Casein gene targeting studies. (a) Structure of the target locus, targeting construct and targeted locus after homologous recombination with the vector. (b) PCR reactions from 11 candidate clones after electrophoresis. $(+)$ is positive control DNA; samples 105 and 712 are negative for $\beta$-casein. Candidate clones show the expected band and an additional nonspecific band of unknown origin. (c) PCR reactions were digested with restriction enzymes to determine whether the targeting-specific band contains the expected restriction sites (Kpn I and Xba I). 


\section{Conclusions}

Gene targeting in livestock will provide opportunities for improving the repeatability and regulation of transgene expression. The main impact of the development of this technology is likely to be within the biotechnology industry rather than agricultural industries, and will alter the economics of the production of pharmaceutical proteins in the mammary gland of transgenic sheep, cattle and goats. In social terms this means that gene targeting in livestock is likely to make it possible for the biopharming industry to develop new products of lower economic value and hence, to expand the proportion of society that stands to benefit. The practical limitations of targeting in livestock include the relative inefficiency of the nuclear transfer procedure and the apparent association of developmental abnormality with the period of time that the nuclear donor cell is maintained in culture. There is also a fundamental problem associated with gene targeting at loci that are silent in the nuclear donor cell; the absolute targeting frequency at silent loci appears to be much lower than at active loci. In addition, the inapplicability of promoter traps at silent loci is associated with a high background of nontargeted clones and greatly complicates the verification of targeted clones. In both expressed and non-expressed genes there is a serious problem associated with senescence of the nuclear donor cell. We believe that these are challenges of high priority not only for applications in livestock, but also for somatic targeting in human adult stem cells with potential therapeutic application in human medicine.

\section{References}

Baguisi A, Behbood E, Melican DT et al. (1999) Production of goats by somatic cell nuclear transfer Nature Biotechnology $17456-461$

Brink MF, Bishop MD and Pieper FR (2000) Developing efficient strategies for the generation of transgenic cattle which produce biopharmaceuticals in milk Theriogenology 53 139-148

Campbell KH, McWhir J, Ritchie WA and Wilmut I (1996) Sheep cloned by nuclear transfer from a cultured cell line Nature 380 64-66

Cibelli JB, Stice SL, Golueke PJ, Kane JF, Jerry J, Blackwell C, Ponce de León A and Robl IM (1998) Cloned transgenic calves produced from nonquiescent fetal fibroblasts Science 280 1256-1258

Clark AJ, Bessos H, Bishop JO et al. (1989) Expression of human anti-hemophilic factor IX in the milk of transgenic sheep BioTechnology 7 487-491

Clark AJ, Burl S, Denning C and Dickinson P (2000) Gene targeting in livestock: a preview Transgenic Research 9 263-275

Dai Y, Vaught TD, Boone J et al. (2002) Targeted disruption of the $\alpha-1,3$-galactosyltransferase gene in cloned pigs Nature Biotechnology $20251-255$

Denning C, Burl S, Ainslie A et al. (2001a) Deletion of the $\alpha(\mathrm{T}, 3)$ galactosyl transferase (GGTA1) gene and the prion protein $(\operatorname{Pr} P)$ gene in sheep Nature Biotechnology $19559-562$

Denning C, Dickinson P, Burl S, Wylie D, Fletcher J and Clark AJ (2001b) Gene targeting in primary fetal fibroblasts from sheep and pig Cloning and Stem Cells 3221-231
Di Berardino M (2001) Animal cloning - the route to new genomics in agriculture and medicine Differentiation 68 67-83

Ebert K, Selgrath J, Di Tullio P, Denman J, Smith T, Memon M, Schindler I, Monastersky $G$ and Gordon K (1991) Transgenic production of a variant of human tissue plasminogen activator in goat milk: generation of transgenic goats and analysis of expression BioTechnology 9 8335-8338

Eggan K, Akutsu H, Loring J, Jackson-Grusby L, Klemm M, Rideout WM, Yanagimachi $\mathbf{R}$ and Jaenisch R (2001) Hybrid vigour fetal overgrowth and viability of mice derived by nuclear cloning and tetraploid embryo complementation Proceedings National Academy of Science USA 98 6209-6214

Eggan K, Rode A, Jensch I et al. (2002) Male and female mice derived from the same ES cell clone by tetraploid complementation Nature Biotechnology 20 $450-459$

Evans MJ and Kaufman MH (1981) Establishment in culture of pluripotential cells from mouse embryos Nature 292 154-156

Gordon JW and Ruddle FH (1981) Integration and stable germ line transmission of genes injected into mouse pronuclei Science 214 1244-1246

Gordon JW, Scangos GA, Plotkin DJ, Banbosa JA and Ruddle R (1980) Genetic transformation of mouse embryos by microinjection of purified DNA Proceedings National Academy of Sciences USA 777380 7384 
Hammer RE, Pursel VG, Rexroad CE, Jr, Wall RJ, Bolt D], Ebert KM, Palmiter RD and Brinster RL (1985) Production of transgenic rabbits, sheep and pigs by microinjection Nature 315 680-683

Harrison SJ, Guidolin A, Faast R, Crocker LA, Giannakis C, d'Apice AJF, Nottle MB and Lyons I (2002) Efficient generation of $\alpha(1,3)$ galactosyltransferase knockout porcine fetal fibroblasts for nuclear transfer Transgenic Research 11 143-150

Humpherys D, Eggan K, Akutsu $H$, Hochedlinger K, Rideout WM, Biniszkiewicz D, Yanagimachi $R$ and Jaenisch R (2001) Epigenetic instability in ES cells and cloned mice Science 293 95-97

Jaenisch R and Mintz B (1974) Simian virus 40 DNA sequences in DNA of healthy adult mice derived from preimplantation blastocysts injected with viral DNA Proceedings National Academy of Sciences USA 71 1250-1254

Kato Y, Tani T, Sotomaru Y, Kurokawa K, Kato J, Doguchi H, Yasue $H$ and Tsunoda $Y$ (1998) Eight calves cloned from somatic cells of a single adult Science 282 2095-2098

Keefer CL, Baldassarre H, Keyston R et al. (2001) Generation of dwarf goat (Capra hircus) clones following nuclear transfer with transfected and nontransfected fetal fibroblasts and in vitro-matured oocytes Biology of Reproduction $\mathbf{6 4} 849-856$

Kubota C, Yamakuchi H, Todoroki J, Mizoshita K, Tabara N, Barber M and Yang X (2000) Six cloned calves produced from adult fibroblast cells after long-term culture Proceedings National Academy of Sciences USA 97 990-995

Lanza RP, Cibelli JB, Blackwell C et al. (2000) Extènsion of cell life-span and telomere length in animals cloned from senescent somatic cells Science $28866.5-669$

Lai L, Kolber-Simmonds D, Park K-W et al. (2002) Production of $\alpha-1,3$-galactosyltransferase knockout pigs by nuclear transfer cloning Science 2951089 1092

Loi P, Ptak G, Barboni B, Fulka J, Jr, Cappai P and Clinton M (2001) Genetic rescue of an endangered mammal by cross-species nuclear transfer using post-mortem somatic cells Nature Biotechnology 19 962-964

McCreath KJ, Howcroft J, Campbell KHS, Colman A, Schnieke AE and Kind A) (2000) Production of genetargeted sheep by nuclear transfer from cultured somatic cells Nature 405 1066-1069

Palmiter R, Brinster R, Hammer R, Trumbauer M, Rosenfeld M, Birnberg $N$ and Evans $R$ (1982) Dramatic growth of mice that develop from eggs microinjected with metallothionein-growth hormone fusion genes Nature $300611-615$
Piedrahita J (2000) Targeted modification of the domestic animal genome Theriogenology 53 105-116

Prather RS, Barnes FI, Sims MM, Robl IM, Eyestone WH and First NL (1987) Nuclear transplantation in the bovine embryo: assessment of donor nuclei and recipient oocyte Biology of Reproduction 37859 866

Rideout W, Eggan K and Jaenisch R (2001) Nuclear cloning and epigenetic reprogramming of the genome Science 293 1093-1098

Rideout W, Wakayama T, Wutz A, Eggan K, Jackson-Grusby L, Dausman J, Yanagimachi R and Jaenisch R (2000b) Generation of mice from wild type and targeted ES cells by nuclear cloning Nature Genetics 24 109-110

Robertson E, Bradley A, Kuehn M and Evans M (1986) Germ-line transmission of genes introduced into cultured pluripotential cells by retroviral vector Nature 323 445-448

Schnieke AE, Kind AJ, Ritchie WA, Mycock K, Scott AR, Ritchie M, Wilmut I, Colman A and Campbell KHS (1997) Human factor IX transgenic sheep produced by transfer of nuclei from fetal fibroblasts Science $2782130-2133$

Thomas KR and Capecchi MR (1987) Site-directed mutagenesis by gene targeting in mouse embryo-derived stem cells Cell 51 503-512

Thompson S, Clarke AR, Pow AM, Hooper ML and Melton DW (1989) Germ line transmission and expression of a corrected HPRT gene produced by gene targeting in embryonic slem cells Cell 56 313-321

Van Reenen C, Meuwissen T, Hopster H et al. (2001) Transgenesis may affect farm animal welfare: a case for systematic risk assessment fournal of Animal Science 79 1763-1779

Wakayama T and Yamaguchi R (2001) Mouse cloning with nucleus donor cells of different age and type Molecular Reproduction and Development 58376 383

Wakayama T, Rodriguez I, Perry A, Yanagimachi R and Mombaerts P (1999) Mice cloned from embryonic stem cells Proceedings National Academy of Sciences USA 9614 984-14989

Willadsen SM (1986) Nuclear transplantation in sheep embryos Nature 320 63-65

Wilmut I, Schnieke AE, McWhir J, Kind AJ and Campbell KHS (1997) Viable offspring derived from fetal and adult mammalian cells Nature 385810 813

Wright G, Carver A, Cottom D, Reeves D, Scott A, Simons P, Wilmut I, Garner I and Colman A (1991) High-level expression of active human alpha-1. antitrypsin in the milk of transgenic sheep BioTechnology $9830-834$ 